\title{
Water Footprint Assessment of a Tea Product in Sri Lanka: A Case Study of Black Tea and Selected Tea Flavours
}

\author{
Wahala W.M.P.S.B. ${ }^{1}$, Senadheera D.K. L. ${ }^{{ }^{*}}$ and Lugoch D. ${ }^{3}$ \\ ${ }^{1}$ Department of Eco business, Sabaragama University of Sri Lanka, Belihuloya, Sri Lanka \\ ${ }^{2}$ Carbon Consulting Company, Sri Lanka \\ ${ }^{3}$ Federal University of Rio Grande do Sul, Brazil. \\ *lakminisenadheera@gmail.com
}

\begin{abstract}
The rising global population and depleting aquifers will lead to a global water crisis in different perspectives. In this context business world will face physical risk, reputational risk, regulatory risk, and financial risk that may translate into increased costs and/or reduced revenues. Presently most of the corporate sector is working towards to efficient water management in their business operations to overcome the farseeing water related risks. Water footprint is the one of the emerging tool to assess the total impact to the water by an entity. This study emphasizes the business valve of estimation of product water footprint for a Sri Lankan tea product to capture the competitive advantage in global market.
\end{abstract}

The aim of this study is to assess the 'virtual water footprint' through life cycle of a tea production, mainly focusing on the fresh water consumption starting from the cultivation stage of green tea leaves and continuing on to tea processing and transportation to finally the packaging stage. The study distinguishes between three types of impact: evaporation of infiltrated rainwater for tea growth (green water use), withdrawal of ground- or surface water for irrigation or processing (blue water use) and water pollution during growth or processing. The latter impact is quantified in terms of the dilution volume necessary to assimilate the pollution (Gary water). For the study, virtual water footprints of six flavours of tea products were analysed according to the water footprint manual published by water Footprint Network.

According to the study, the average virtual water footprint of the $1.5 \mathrm{~g}$ tea bag from the green leaf production up to the manufacturer's gate for black tea is 19.8 liters (l), green tea is 18.46 1 and average virtual water footprint for flavoured tea is $20.221 \pm 7.041$ per tea bag. Average virtual water footprint for the ingredients including raw tea and flavours contribute $93.6 \%$ for the total water footprint and the $6.4 \%$ of the total water footprint accountable for the virtual water footprint of the packaging materials.

Keywords: Product water footprint, Virtual water, Tea 